\title{
Economia e Política em Wolfgang Streck
}

\author{
Economics and Politics in Wolfgang Streck
}

Economia y Política en Wolfgang Streck

Recebido em 20-02-2020

Modificado em 30-03-2020

Aceito para publicação em 11-04-2020

\section{do:}

https://doi.org/10.47456/simbitica.v7i3.33708

\section{Octávio Fonseca Del Passo}

ORCID: 0000-0001-6348-5365

Doutorando em Ciência Política pela Universidade Estadual de Campinas (UNICAMP) e bolsista pela CAPES. E-mail: octaviodelpasso@gmail.com

\section{Resenha}

STRECK, Wolfgang (2018), Tempo comprado. A crise adiada do capitalismo democrático.

São Paulo, Boitempo, 235p.

“[...] a história da crise do capitalismo tardio desde os anos 1970 afigura-se como desenvolvimento da tensão, muito antiga e fundamental, entre o capitalismo e a democracia".

(Streck, 2018:54)

Publicado recentemente no Brasil, o livro "Tempo Comprado. A crise adiada do capitalismo democrático" é resultado de uma conferência proferida por Streck em 2012, oportunidade em que o autor realizou uma crítica à crise econômica de 2008, demonstrando grande habilidade de análise dos dados econômicos. Sob a noção de que as leis econômicas são projeções das relações de poder entre as classes sociais e de que as crises econômicas são conflitos distributivos, o autor prega que o equilíbrio sócio-político só é atingido através do desequilíbrio econômico e o adiamento desse problema é possível, mas sempre provisório. Para avançar sobre essas afirmações, o autor utiliza a Teoria Crítica desenvolvida na Escola 
de Frankfurt como base teórica que ampara seus resultados, os quais têm a pretensão de não ser apenas uma leitura macroeconômica e política da crise, mas também da democracia.

O nome da Escola de Frankfurt foi cunhado em referência à localização onde se encontrava um grupo de pensadores compostos por Marcuse, Fromm, Pollok, Adorno, Horkheimer e Wittfogel. A produção desses teóricos situa-se no contexto político do colapso da social-democracia alemã e ficou conhecida pela análise com base em conceitos como o de indústria cultural, manipulação, autoritarismo, racionalidade capitalista e pela crítica instrumental. A produção era inspirada na tríade Marx (sobretudo o jovem), Weber e Freud. Este teve papel fundamental, pois a contribuição mais notória da teoria crítica da sociedade desenvolvida por esse grupo de autores foi talvez o toque do que podemos chamar de "psicologização" dos problemas sociais.

O livro de Streck é instigante porque ele ousa, partindo dessa tradição teórica, fazer algumas análises prospectivas que não são facilmente digeridas como pontos consensuais, o que torna o seu livro exposto a demasiadas críticas. Um exemplo é a leitura de que ocorrerá uma libertação do capitalismo e de seus mercados da democracia enquanto democracia de massas - não dos Estados aos quais eles são dependentes. Desse modo, prevê o autor, haverá um longo período de baixo crescimento econômico, elevada desigualdade social e endividamento geral. A conclusão é que a situação se tornará insustentável, posto que a relação do capitalismo com a democracia é uma relação ocasional e funcional à própria acumulação de capital e só foi possível no período do pós-guerra. Assim, se

[...] democracia significa que a justiça social não pode ser absorvida pela justiça de mercado, então o objetivo primordial, em termos de política democrática, deveria consistir em retroceder em relação às destruições institucionais causadas por quatro décadas de progresso neoliberal, defendendo e restaurando da melhor maneira possível os restos das instituições políticas que permitiriam modificar ou até substituir a justiça de mercado pela justiça social (Streck, 2018:209).

Mais precisamente, a tese de Streck é que, além de os capitalistas não terem mais motivos para manter a democracia, eles não têm mais condições para realizar tal feito porque para isso é necessário que se compre mais tempo com mercadorias e serviços para prorrogar a revolta dos que vivem do trabalho diante do aumento exponencial da desigualdade e do enriquecimento dos que vivem dos juros, situação que é descartada diante dos dados analisados da crise de 2008 .

O fato de o autor partir da Teoria Crítica da Escola de Frankfurt, que tem como pressuposto heurístico uma relação de tensão entre a vida social e a economia baseada na valorização do capital, o leva a entender que a crise econômica prevista por essa teoria para o 
final dos anos 60 e começo dos anos 70 foi adiada por quarenta anos e que as tensões sociais decorrentes dela ainda estão presentes, embora de outro modo. Para Streck, as etapas históricas das crises que tencionaram a democracia chegaram a um ponto em que, a partir de 2008, se tornou inadiável o divórcio entre capitalismo e democracia. Em síntese, o entendimento do autor é que a "compra de tempo" que permitiu o adiamento da crise decorrente da tensão entre o capitalismo e a democracia mudou a natureza desta e as suas causas agora são outras. Esse postulado faz com que além de uma crítica à Teoria Crítica da Escola de Frankfurt, as intervenções de Streck se tornem ao mesmo tempo um desenvolvimento dela e uma atualização das suas causas.

A maneira como o autor desenvolve seus argumentos deixa a entender que para ele essa atualização da Teoria Crítica também deve ser realizada sob a perspectiva da busca de qual será a nova reação à crise, uma vez que diante de diferentes causas, as respostas devem ser outras. Mais do que uma afirmação óbvia, esse pressuposto do autor se enquadra na perspectiva teórica adotada por ele, segundo a qual o elucidativo dos casos são os processos e não o estado das coisas - ou o estado enquanto parte do processo e não enquanto estrutura. Além disso, a importância da questão da continuidade temporal não está dissociada do momento e do lugar em que os fenômenos ocorrem, de modo que o tempo diacrônico histórico também é importante em sua análise.

O autor utiliza um amplo banco de dados da macroeconomia da Europa ocidental para embasar a análise que ele faz do período do pós-guerra, tempo em que devido à correlação de forças desfavoráveis ao empresariado, a burguesia foi levada a realizar um pacto com as classes populares para que houvesse a melhora de sua qualidade de vida. Essa aliança teve como base o consumo de massa e a oferta de serviços públicos ou, nas palavras do autor, essa foi a maneira que os capitalistas encontraram para "comprar tempo" e conseguir adiar a crise. Neste contexto, o autor menciona que a democracia parlamentar foi o regime que sustentou esse pacto, mas que provavelmente acabará com ele.

No entanto, o primeiro imprevisto ocorreu já no início da década de 1970 devido à estagnação econômica. Antes, portanto, do advento do neoliberalismo. A saída dos governos da Europa ocidental foi liberar dinheiro no mercado em forma de crédito, o que resultou em disparada da inflação e exigiu, por sua vez, a elevação dos juros. Essa conjuntura fez com que os Estados se endividassem ${ }^{1}$, porque para manter a paz entre as classes no pós-guerra era

\footnotetext{
${ }^{1} \mathrm{O}$ endividamento do Estado tem um significado mais amplo na obra do autor, pois ele é um fenômeno políticoeconômico característico do capitalismo, e não apenas dos regimes democráticos. É uma autorregulação em que o equilíbrio sócio-político só é atingido através do desequilíbrio econômico e o adiamento dessa questão é
} 
preciso continuar injetando dinheiro na economia a fim de garantir o pacto que sustentava a democracia, pois esse investimento teve como centro as políticas sociais, que garantiu, inclusive, a retomada da economia nos anos 80. Desse modo, a relação entre processo inflacionário, dívida pública e "compra de tempo" é direta. A escalada da inflação vinha corroendo o poder de compra que o "povo do mercado" havia oferecido no pacto realizado com o "povo do Estado" no pós-guerra e o combate à inflação foi realizado por meio do aumento dos juros, que por sua vez impactou no aumento da dívida pública. Ao aliviar a inflação com o aumento da dívida foi possível manter o padrão de consumo do "povo do Estado", o que resultou em nova compra de tempo.

A partir dessa década, os capitalistas passaram a temer que o Estado lhes desse um calote devido ao grande endividamento que haviam contraído. Isso gerou, segundo o autor, uma situação propícia ao período de políticas de austeridade com a intenção de cortar a dívida pública, o que, na prática, significava cortar os investimentos em programas sociais. Foi então que os capitalistas passaram a incentivar o endividamento privado como forma de sustentar o padrão de funcionamento dos mercados e, por consequência, o pacto democrático, comprando tempo mais uma vez. Isso foi feito através da desregulamentação dos mercados financeiros, que acabou estourando em 2008, a partir de quando o Estado voltou a se endividar na tentativa de conter a crise.

Os dados do portal Trading economics ${ }^{2}$ mostram que algumas das principais economias capitalistas do mundo, como Japão, EUA, França e Alemanha, já possuíam, mesmo com os cortes em políticas sociais, uma curva com trajetórias predominantemente ascendentes, se considerarmos a série histórica de 1980 até 2020. Desse modo, o endividamento de alguns Estados teve um incremento, em diferentes razões, na sua taxa de crescimento com a crise de 2008. Mas ela já era crescente. Ainda há que se notar que a Alemanha, de 2010 a 2020, já conseguiu reverter essa trajetória e a dívida está caindo. É um detalhe importante de ser observado porque afirmar que ela voltou a crescer pode sugerir que antes havia estagnação ou decréscimo. A produção de trilhões de euros e dólares, impressos pelo Banco Central Europeu e pelo Federal Reserve Board (FED), após o estalar da crise de 2008 garantiu a liquidez do mercado e a manutenção do sistema de pagamentos. Foi por meio de estatização que os Estados europeu e estadunidense possibilitaram que o sistema bancário fosse salvo.

possível, mas provisório. Quando esse equilíbrio se torna improdutivo, ele vira um desequilíbrio social que precisa de um novo ponto de equilíbrio que seja politicamente responsável e economicamente irresponsável.

${ }^{2}$ Cf. em: https://pt.tradingeconomics.com/country-list/government-debt-to-gdp 
Mas, se os bancos se salvaram, as famílias continuaram endividadas, sendo ainda um grande entrave para o modelo de financiamento que sustentou a economia dos EUA desde os anos 1970. Nesse sentido, o raciocínio do autor aponta que vivemos hoje uma situação em que os governos já se utilizaram da política de juros, do endividamento do Estado e do endividamento das famílias, de modo que não restam muitas alternativas. A questão que permanece em aberto é a afirmação de que não há mais saída para o capitalismo e que a crise de 2008 representa o começo do fim do capitalismo democrático.

Segundo o autor, partindo desse ponto podemos concluir que Marx estava correto ao mostrar que com a ascensão do capitalismo a produção ganha um caráter social crescente que entra em conflito com as relações de propriedade. No caso da Europa ocidental, o que deixou a situação evidente foi o fato de que o endividamento do Estado e o conflito entre o caráter social da produção e apropriação privada dos lucros seguem crescentes. Ao colocar a crise de 2008 como uma etapa da sequência histórica de crises, Streck realiza um paralelo entre o retrocesso em termos de desigualdade e distribuição de renda e a arena dos conflitos distributivos, que se deslocou do mercado de trabalho (na fase inflacionária) para a política social (na fase de endividamento dos Estados), chegando ao mercado financeiro privado (na época da "financialização" após a crise de 2008). É uma crise que resultou do acúmulo da crise das finanças públicas e da economia real, porque a crise bancária se vincula à crise do Estado por meio do dinheiro e à economia real por causa do crédito e a crise das finanças públicas se vincula à economia real por meio das despesas e receitas públicas.

Para Streck, a atual crise da democracia tem relação com a percepção real de que há uma transferência da tomada de decisão dos governos para as agências supranacionais que detêm os títulos das dívidas dos Estados, como o Fundo Monetário Internacional (FMI) e o Banco Mundial (BM). O autor não desenvolve a diferença entre essas instituições e as agências de rating, mas a leitura do livro sugere que elas estão todas sob a mesma ideologia. Embora este seja um fato contestável, é a partir desse conjunto de afirmações que Streck anuncia a existência de dois povos, o "povo do Estado", que elege governos, e o "povo do mercado", para quem os governos eleitos, de fato, governam. Sem explicitar o que entende por Estado e mercado, o autor diferencia esses povos, o que parece ser uma provocação às teorias da democracia que admitem que o Estado se financia exclusivamente por meio de seus contribuintes.

Para o autor, cada um desses povos têm princípios diferentes. O "povo do Estado" é baseado na justiça social e o "povo do mercado" no preço, de modo que uma distinção entre 
justiça social e justiça mercadológica é criada, já que a política democrática no capitalismo é pressionada a dividir de modo desigual os "frutos do mercado"3. Na visão do "povo do mercado", a justiça social é um princípio corrupto, uma vez que é preciso alocar os recursos com embasamento político, e não meritocrático. Segundo os princípios do "povo do mercado" a justiça social foi feita para aqueles que são os perdedores no mercado.

É neste sentido que Streck desenvolveu um conceito de crise de legitimidade a partir dos acontecimentos que se desenrolaram desde os anos 60 e 70 e que incluem o Estado, o capital e os dependentes de salário. Os conflitos na distribuição resultam de os lucros dependerem cada vez mais de menores salários, de modo que as crises do capitalismo não têm origens técnicas, mas políticas, da ordem da confiança do capital (empresários e empresas). Se ele percebe que não conseguirá realizar seus lucros, não realiza os investimentos e os salários desaparecem. De tal modo, o capitalismo não é um estado natural das coisas, mas uma ordem social que requer ser formada e legitimada pelo Estado. A grande mobilização de dados econômicos também serve para analisar a democracia pois é a partir desses dados que o autor realiza uma crítica à Teoria Crítica de Frankfurt. Segundo Streck, essa teoria desistiu do central no marxismo (a teoria econômica) quando assumiu a teoria do Estado e da democracia porque seus pensadores passaram a superestimar a capacidade de planejamento do Estado e subestimar a capacidade do capital de desenvolver estratégias. Esse fato mostrou que as teorias marxistas não estavam preparadas para lidar com a autorregulação do mercado moderno e a rápida aceitação cultural que as formas de vida adaptadas ao mercado tiveram nas classes populares.

Ademais, a expectativa que essa teoria tinha de que as crises econômicas deslegitimariam o sistema capitalista foram todas frustradas. O problema central para Streck é, portanto, que à medida que o Estado neoliberal é implementado para responder aos anseios do "povo do mercado", os credores desse Estado endividado se tornam os seus mandatários e as "crises surgem quando aqueles que controlam os meios de produção imprescindíveis acreditam que existe o perigo de não serem remunerados de acordo com suas concepções de justiça de mercado" (106). Ou seja, o problema é que o neoliberalismo é a transformação do Estado da "justiça social” no Estado que gere os negócios da burguesia.

\footnotetext{
${ }^{3}$ É interessante notar que o autor utiliza a expressão "frutos do mercado" e não "frutos do trabalho", do mesmo modo que utiliza "povo do mercado" e não burguesia. Embora se reivindique marxista o autor não se utiliza desses conceitos tão bem desenvolvidos por diversos autores. Essa imprecisão nos conceitos traz dificuldades ao autor, que acaba adotando enfoques liberais.
} 
Portanto, a superação da crise por meio da política econômica consiste em negociar uma espécie de equilíbrio entre as expectativas de rendimento dos proprietários do capital e suas exigências em relação à sociedade, por um lado, e as expectativas salariais e de emprego dos beneficiários de salários fixos, por outro - esse equilíbrio o capital considera suficientemente justo para continuar a empenhar-se na criação de bem-estar (Streck, 2018:71).

Ocorre, contudo, que a conclusão de Streck nos parece incompatível com uma visão marxista do Estado. A leitura do livro dá a entender que a tese de Streck (2018:209) pressupõe que o Estado capitalista é neutro e o problema é o neoliberalismo. Tanto na primeira citação, na qual o autor sugere que democracia deveria "consistir em retroceder em relação às destruições institucionais causadas por quatro décadas de progresso neoliberal", quanto nessa citação em que o autor sugere que devemos buscar um equilíbrio entre o capital e o trabalho, temos a impressão que o Estado capitalista é um bom ponto de equilíbrio. Ainda notamos que Streck, se referindo aos povos "do Estado" e "do mercado", não adota uma Teoria do Estado de maneira clara e objetiva, de modo que fica a impressão de que o Estado, independentemente do seu tipo e da sua forma joga a favor da "justiça social". As afirmações de que, hoje, o Estado joga a favor do "povo do mercado" soa como uma deformação causada pelo neoliberalismo e que em outros períodos não foi assim. Se o Estado joga pela "justiça social" significa que ele tende mais aos dominados que aos dominadores. É um Estado que se orienta pela justiça material e pela justiça não formal, e não apenas pela "justiça do mercado", atuando para além da distribuição dos serviços e das mercadorias através da meritocracia. Em síntese, a maneira que o autor aborda o tema da "justiça social" dá a entender que é o neoliberalismo o problema a ser combatido, e não o Estado capitalista. $\mathrm{O}$ autor acaba por combater a forma, e não o conteúdo.

Sustentamos que a retomada da análise empírica da economia faz com que Streck se descuide do plano político, colocando o papel do Estado capitalista enquanto instituição com caráter de classe dominante à margem de sua análise. Uma consequência é a transposição da análise estrutural do capitalismo para a correlação de forças conjunturais através de explicações apenas econômicas, desconsiderando-se o tipo de Estado, a sua forma e os tipos de regimes políticos, ou seja, sem que se proceda a uma análise do plano político de cada Estado. Assim, temos passagens no livro em que o capitalismo, um modo de produção, é colocado lado a lado com a democracia, um regime político. Isso fica claro na epígrafe dessa resenha, na qual o autor sugere uma tensão entre um modo de produção e um regime político, embasando-se exclusivamente em dados econômicos. Temos diversas pesquisas mostrando a existência do capitalismo enquanto modo de produção tanto em regimes políticos 
democráticos quanto em regimes políticos ditatoriais ou de inclinações fascistas. Ou seja, a variação da forma do Estado e do regime político ocorre com grande frequência e naturalidade no capitalismo.

Em resumo, o livro tem grande mérito na análise econômica da crise de 2008 e da sua possível gênese na década de 1970. No entanto, tem uma lacuna teórica sobre o Estado, o que não ajuda a sustentar os argumentos no campo da política. A ideia que Streck defende, da existência de dois povos e a de que um deles têm a missão de realizar a justiça social sem que se anuncie uma Teoria do Estado torna seus argumentos menos convincentes, pois deixa flancos abertos ao escorregar na concepção liberal de Estado, que é aquele que entende o Estado como um instrumento neutro, de modo que não realiza a justiça social porque está aparelhado por grupos que o manipulam, quase que diretamente, em seu benefício. 